\title{
A study on Neuromarketing as Emerging Innovative Market Research Strategy: An Interpretive Structural Model Approach
}

\author{
Prof. (Dr.) Manish Madan', Ankita Popli \\ ${ }^{1}$ Professor Rukmini Devi Institute of Advanced Studies, Rohini, Delhi, India \\ ${ }^{2}$ Assistant Professor Rukmini Devi Institute of Advanced Studies, Rohini, Delhi, India
}

\begin{abstract}
The field of neurosciences has advanced to such an extent that even minute neuronal activities can be measured and studied. These advances created paradigm shifts in the knowledge basis of diversified fields. Medicine, finance, computers, economics are a few of them. Unsubstantial efforts were put in to utilize this technology to better understand the consumer and develop better marketing strategies until, neuromarketing came into existence. Neuromarketing uses the latest advances in brain scanning to reveal the desires, expectations and hidden restraints of consumers. These revelations about the "Human Black-Box" act as an imperative tool for businesses to strategize their marketing attempts. Though the concept has created ripples in the marketing industry all over the world, it is yet to penetrate in Indian marketing scenario. The importance of acceptance of neuromarketing in India lies upon the fact that corporations all over the world see a huge potential in the Indian markets. Therefore, it becomes extremely important to understand the preferences of the Indian consumers. Relatively a newborn in the Indian society, neuromarketing is waiting for a strong academic and experimental platform on which, it can stand firmly. This paper is an attempt to identify the key variables that influence the acceptance of neuromarketing in the Indian society. The interrelationships of these variables have been established using Interpretative Structural Modeling. The variables have been categorized in accordance with their driving power and dependence. Based on the findings, a structural framework has been established that provides an insight into the factors will help neuromarketing to flow smoothly into the Indian society.
\end{abstract}

Keywords: Neuromarketing, Human Black-Box, Interpretative Structural Modeling, driving power, dependence, Acceptance

\section{INTRODUCTION}

The traditional methods are fading away with scientific methods taking a plunge into the field of market research. Neuromarketing is the recent technique in market research that is attracting many eyeballs. As the word suggests, Neuromarketing is an unusual blend of Neuroscience and Marketing. The amalgamation of the two distinct branches of study has given rise to the scientific mapping of the brain for the purpose of analysis of the brain activity and its response to a marketing stimulus. It can be seen as a window created by scientific techniques to peep inside the 'black box'-the brain. The spark was ignited in $19^{\text {th }}$ century with the experiment carried out by Angelo Mosso which concluded that the blood flow increased in the brain during a mental activity. Later, in 1990's, psychologists at Harvard University developed the concept which was termed at Neuromarketing by Ale Smidts in the year 2002. Since then, it has been growing and developing like wildfire. Bright House Institute for thought sciences became the first company in 2002, to use neuroimaging in unfolding the secrets of the brain. Since this technology came into limelight, lots of techniques were used to provide accurate analysis and data to the researchers. Some of these included the use of Pupil meters, Galvanic Skin Responses, Steady State Topography, Magneto Encephalography, Positron Emission Topography, Electroencephalography and fMRI. Out of these, fMRI is the most widely accepted and used technique. It helps in scanning and detecting the changes in the blood flow in the brain due to any external stimuli, which in this case is the marketing stimulus. This paper also covers the very famous and an important experiment conducted by Read Montague which was published in Neuron in 2004. According to the neuromarketing researchers, the human brain can be categorized into three parts. The 'Triune Brain Model' developed in the 1960's subdivides the brain into three parts that are interrelated to each other. However, even after being correlated, they perform distinct functions that control various aspects of the human behavior. The activation of any of these during a marketing stimulus gives the answer to what action the individual might take and what is the actual response of his subconscious. A neuromarketing pioneer and a branding expert, Douglas Van Praet throws light on the fact 
that branding is basically the expectation of consumers based on memories. In his book, 'Unconscious Branding', he says that most of the decisions of the consumers are unconsciously taken. Therefore, the marketers in today's scenario should focus more upon the question "How did you take the decision", rather than "why did you take the decision". The most important and urgent question or issue, as can be said appropriately, is that, is using the clinical techniques for marketing purposes ethical? Specifically talking about the Indian population, are the people ready to accept and co-operate with this technique. Just ten years after its budding, the concept is already facing raised eye-brows of the critiques. What a person thinks and feels at the subconscious level is a private affair and a marketer trying to get into one's subconscious level may disrupt the privacy of the consumers. Also, it may give rise to unethical practices of making the consumers like those products which may harm them emotionally or physically. For e.g. advertising alcohol in such a way so that it appeals to the customers at the subconscious level may augment the problem of addiction. Likewise, there are many such issues that need to be analysed in this concept. This paper basically informs about what is the concept of Neuromarketing, the description of techniques used by researchers in this concept, its advantages and areas that need to be looked upon. Also, it talks about if the concept is morally correct and should it be used widely. The content also covers the scientific elaborations on the human brain and what are the various "buy-buttons" present inside it. Broadly, the paper throws light on why and why not to use Neuromarketing.

\section{IDENTIFICATION OF VARIABLES}

The objective of all marketing activities is to enhance the overall purchases and thus profits. Advertising is one of the major components of promotional mix and that of marketing communications. Huge amounts are spent every year on advertising. The advertisers hope that customers would remember their brands, eventually buying them. "Marketers are not concerned with how the consumers process the information and how they perceive the same. The marketers and advertisers communicate what they think is right. They are not concerned about communicating the right things in the right manner." People responsible for marketing communications do carry out market research projects, to understand the requirements of the target groups. However, in the word of Charles Young, the market researchers have started questioning the premise that a target consumer would reflect 'what he really thinks' in response to a question in the questionnaire. It cannot be ascertained that the response is exactly in line with what the consumer actually feels. Research reveals that sometimes, the consumers themselves don't know what their real feeling is about a situation. Daniel Wagner says that, "Most of what we know, we don't know, we know". It can be said that consumers would act in a particular manner at the spur of the moment. Sometimes, they know their actual feelings, but do not intend the marketing researcher to know the same. Respondents may be unwilling because they feel the information is embarrassing or private.

In the proposed model, brainstorming sessions were conducted with the experts from industry as well as academicians to identify the relevant variables. After the identification of 35 variables altogether, only 27 were considered, eliminating those that were same in nature. In the next session, another brainstorming session was held in order to establish the relationship among the identified variables. The main purpose of carrying out these brain storming sessions was to gather different viewpoints that helped in identifying the links between the variables that are important in the acceptability of neuromarketing in India. The variables that have been collated together for the purpose of developing an interpretative structural model are elaborated further in detail.

\section{Fast results of market research}

The prospect of neuromarketing is brighter as it contains several benefits as compared to traditional market research techniques (Magaldi, 2012). The techniques of neuromarketing include measuring the brain activities of the subjects at the rate of 2000 times per second. EEG, fMRI and other such methods are used to gain new levels of insights about the consumers' subconscious response towards advertisements, websites and other promotional materials (Regan, 2008). Rather than analyzing survey responses, researchers can get access to the subconscious reactions of consumers within minutes.

\section{Increased sales revenue}

Having sales success in a competitive environment means a lot to the marketers. Neuromarketing capabilities to deliver at the cash register were demonstrated when a magazine publisher put this technique to test. New Scientist Magazine approached Neurofocus to test three cover designs using neuromarketing. The first cover 
design was the winner in terms of emotional engagement, attention and memory. The August issue of the magazine with the same cover saw an increase in the sales by $12 \%$ over the previous year. This is an astonishing figure for the normally quiet month of August for a magazine (Pradeep, 2010).

\section{Accuracy in research}

An estimated \$1 billion is spent on focus groups, in which personal biases and external environment can produce inaccurate information (Magaldi, 2012). Measuring the brain is the most accurate, reliable and actionable form of market research. This is because the subconscious is where the interest, purchase intent and loyalty of brand are formed (Pradeep, 2013). Thus unlike traditional market research methods, the techniques of neuromarketing provide much more accurate results.

\section{Creation of high impact ad-campaigns}

Neuromarketing has an immense potential to drastically change the face of commercial and cause related advertising throughout the world (Morin, 2011). In the advertising world, the response to an ad is of greater importance than the stimuli. Thus is the marketer understands that which area of the brain stores the ad stimulus and its effect on the brand choice, it would definitely increase the ad effectiveness (Ambler, Ionnaides, \& Rose, 2000).

\section{Creation of Brand Preference}

Association of consumers with a brand play a vital role in formation of their preferences towards brands (Walvis, 2007). Neuromarketing makes it possible for the marketers to reach to the subconscious level of the brain where initial interest in the product is developed. With continual research and development, this technique may be used to influence our decisions (Burney, 2012), that would further play a role in forming brand preferences.

\section{Opportunity for New Product Development}

Consumer needs and wants are ever-changing. Identifying and catering to them is a task for any marketer. The complications arise with the fact that consumers are themselves unaware of what they want (Neurosense, 2013). Neuromarketing techniques help to unleash the deep rooted desires of consumers that provide an opportunity for developing new products.

\section{Increased return on investment}

Marketers invest in developing new products so that they can cater to the needs of the market. Consumers invest in products so that they can fulfil their needs and wants. In both the cases, return on investment plays a vital role. For consumers, neuromarketing aims at creating value driven and customer centric products and ads to provide a satisfying return on investment (Fabiano Communications, 2013). For marketers, it is a question of making worldwide investments. Globalization has increased the need of producing and marketing on a worldwide platform. Knowing the behavioral pattern of consumers has a direct impact in the ROI for marketers.

\section{Minimized complexity in Marketing}

It is recommended by researchers that all complex decisions are left by the decision makers for the subconscious. If a decision is more complex, it requires more thought and deliberation (Dooley, 2007). The neuromarketing perspective has that the more complex the product is, its marketing message should be equally simple (Koller, M., 2008).

\section{Ethical permissibility}

Being one of the recent developments in the field of marketing, neuromarketing is one of the effective ways of cutting through the messiness of what consumer wants. However, this technique may prove to be far more effective in manipulating the external consumer behavior. Hence it needs more of controlling and ethical permissibility (Levy, 2009). The Neuromarketing Science and Business Association, which is a global trade association for all having interest in the field of neuromarketing has established an ethical code of conduct for the application of neuroscience in business (Neuromarketing Science \& Business Association, 2013).

\section{Credibility of sources}

The credibility of the information provider is of utmost importance while evaluating the options available. Thus it is essential for marketers to be credible for the information that is being processed from the neural experiments (Zurawicki, 2010). In an experiment conducted by Deppe et al. (2005), it was evident that there was a brand effect that was a major source of trustworthiness of a source, irrespective of its ambiguity. It also shows that neuromarketing may help in drawing a thin line between trustworthiness and awareness of a brand. 


\section{Well established experiments}

There are initiatives arising from well renowned authors and academicians for incorporating the use of neuroscientific methods in marketing. The marketing firms that are trying to establish a link with neural methods are gradually concentrating on the recommendations provided by researchers and academicians. Given the lack of knowledge, the public gets easily frightened with such market research techniques being used (Javor et al, 2013). Thus the academic communities like Plassman et al, (2012), recommend certain standards to be maintained out of which, rigorous and well established experiments form an essential part.

\section{Strong Literature and Academic evidences}

Since the concept is in a budding stage, it is yet to strengthen its paws in the corporate world. Thus is needs a strong base to rely upon. Since the time when neuroscientific techniques began to invade marketing techniques, academicians and researchers rampantly started formulating relevant literature and produced array of thoughts. For neuromarketing to establish, it should refer to peer-reviewed academic research and literature evidences given by the academicians (Reason, 2013).

\section{Availability of funds}

Understanding the functionalities of the human brain requires some sophisticated equipments and experimental set ups. Though certain technologies are not even widely available, those that are, are equally expensive. The research companies need to invest huge amounts in order to acquire and implement the required technologies. For e.g. fMRI is the most widely used and preferred technique. However, the fMRI scanners are very expensive and may be afforded by only large scale research firms (Morin, 2011). A medium sized study could cost from $\$ 94,000$ to $\$ 188,000$ which may vary (Eser, Z., Isin, F. B., \& Tolon, M. ,2011))!

\section{Availability of participants}

For this concept to be successful, availability of participants willing to take part in the experiments is of utmost importance apart from knowledge and ethics. There is ample participation observed in the foreign countries for tests like fMRI (Eser, Z., Isin, F. B., \& Tolon, M. ,2011)). Though the techniques are considered to be harmless, still they hold certain negative impressions among masses. This may hamper the availability of participants (Moore, 2005). Thus it is important to spread awareness about the benefits of these non-invasive techniques of neuromarketing in a country especially like India.

\section{Availability of Instruments}

Technical instruments, which are mostly used in medicine, are required to conduct these neuromarketing experiments (Bercea, M. D. , 2011). According to O'Connel, B., Walden, S., Pohlmann, A. (2011), convergence of traditional marketing techniques with the neuromarketing experiments reveal the unsaid preferences of people. Thus, in accordance with the marketing objectives, suitable techniques should be chosen subject to the availability.

\section{Requirement of expertise in neuroscience}

Till date, neuromarketing experiments have been used by large companies like Coca-Cola, Google, and Walmart etc. As mentioned earlier too, these experiments involve huge sum of investment. Not only the equipments make the cost high, but another factor raises the graph as well. It is the expertise that is required which adds on to the cost (Roberson, 2012). Unless there is involvement of experts in neurosciences, the results from the experiments may prove to be futile.

\section{Requirement of business academicians}

Neuromarketing is a heterogeneous field requiring inputs from an array of fields. It is related to the academicindustrial partnership that yields outputs for both, equally. The involved companies employ academicians, refer to academic literature and established facts in order to formulate a strong base for achieving objectives (Fisher, Chin, \& Klitzman, 2010).

\section{Educating consumers and marketers about techniques used}

For neuromarketing to form a strong grip in the Indian market, it is essential to create awareness about hat techniques are used and why they are used. A Free will frame constitutes of creating awareness, developing understanding and obtaining consent of the participants for a neuromarketing experiment (WILSON, GAINES, \& HILL, 2008). Without these, even if any experiment is conducted, it might be labelled as unethical.

\section{Tracking of unidentified consumer needs}


Neuromarketing can be best understood as a technique that helps in identifying the consumer needs (CiprianMarcel, Lăcrămioara, Ioana, \& Maria, 2009) that are concealed in the human brain (Demirbilek, 2013). It is almost impossible for marketers to track the actual needs of consumers as elements like distrust and unawareness crop in during collection of consumer responses.

\section{Increasing awareness among marketers}

Though this field of marketing is growing like wildfire, it cannot be developed in countries where it is relatively unknown. In order to build its awareness among the marketers, the gap between what the marketers want to know and the information that they get should be minimized. In countries like Canada and Turkey, effluent neuromarketers are making the use of social media to popularize this new context ( True Impact Marketing Inc., 2013).

\section{Adopting relevant new technology}

Major consumer brands have adopted neuromarketing techniques to know the actual consumer preferences (Dooley, 2013). For Indian companies, it is essential to adopt the relevant technologies in order to establish neuromarketing in their system.

\section{Company tie-ups and sponsorships}

As mentioned earlier, neuromarketing is an interface between the academic and business world that involves inputs from an array of backgrounds. For researchers to carry out these experiments there is a need for tie-ups or sponsorships from the corporate so that the benefit is touted to both the involved parties.

\section{Obtaining free will of participants}

Creating awareness and educating consumers is not enough for them to get convinced to participate in the neural experiments. Especially in a conservative country like India, where people get frightened with routine EEG and MRI, participation with free will is a dicey situation. As discussed earlier too, it would be an ethical violation if there is lack of any one of the three i.e. knowledge, consent or understanding (WILSON, GAINES, \& HILL, 2008).

\section{Training and development of employees}

Employees of an organization can readily adapt to an expected behavior if they are provided with the required training and code of ethics (carte blanche, 2013). For Indian companies to successfully adopt this recent breakthrough, the employees should be trained enough so that they get acquainted with the required skills. This should be apart from acquiring people with the required skill set to conduct and interpret the experiments.

\section{Tapping the felt need for new technology}

Neuromarketing aims at explaining and quantifying the unexplained needs and requirements at the subconscious level (Barkin, 2013). It aims at studying the cognitive and affective zones of human behavior (Ozdemir \& Koc, 2012). The traditional methods of market research often will not provide accurate results as individuals are themselves unaware of their needs at the subconscious level. Therefore, there is a felt need all across the globe to peep inside the black box to determine the human needs and desires.

\section{Trust of research firms and consumers}

Moving from and old tradition to something new requires firm base and trust. Neuromarketing is an attempt to shift the paradigm of the traditional market research methods towards brain research. It requires people and the masses to trust the new methods. Here, the role of academicians is of utmost importance as they are the major communicators who link both (Fisher, Chin, \& Klitzman, 2010). Also, adhering to ethical codes of conduct and effective communication will surely help in developing and maintaining trust of public and companies in brain science research (Genco, 2013).

\section{METHODOLOGY}

Descriptive research has been applied, describes data and characteristics about the population or phenomenon being studied. The researchers have interviewed experts and as far as the secondary data is concerned that was obtained from web sites, journals etc. There are 37 different parameters, which are under nine dimensions were tested by ISM technique done with the help of expert opinions. Interpretative Structural Modeling is a process in which a set of interlinked elements are given a form of a comprehensive and a systematic model (Agarwal, Shankar, \& Tiwari, 2007). This technique helps in formulating the inter-relationship among the identified 
variables. The model formulated with the help of ISM depicts the structure or a system of a complex issue in graphical and a flowchart form. The technique is basically based on the interpretations of experts and the group who are the decision makers of how and why the variables are inter-related. An integrated and overall structure is extracted out of these inter-relationships.

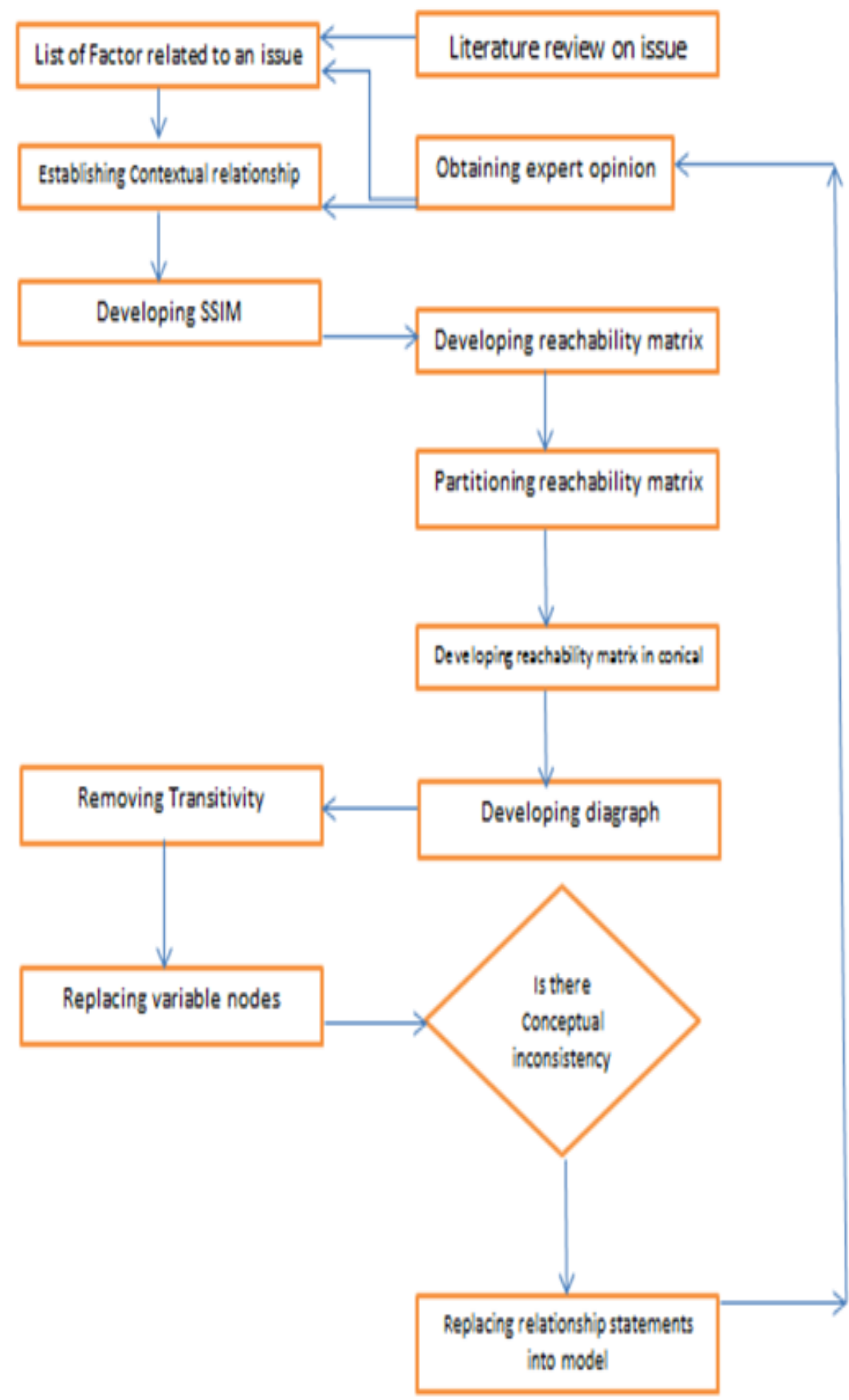

Fig 1: Flow Chart to Prepare ISI Model

In this research, ISM is applied to present a framework for modeling the factors affecting the buying intentions of customers in the telecom industry on the basis of market mix and service quality. Various steps involved in the ISM technique are illustrated (Agarwal, Shankar, \& Tiwari, 2007). 


\section{Structural self-interaction matrix (SSIM)}

The variables affecting the acceptability of neuromarketing in India are Fast results of market research (1), Increased sales revenue (2), Accuracy in research (3), Creation of high impact ad-campaigns (4), Creation of brand preference (5), Opportunity for new product development (6), Increased return on investment (7), Minimized complexity in research (8), Ethical permissibility (9), Credibility of sources (10), Well established experiments (11), Strong literature and academic evidences (12), Availability of funds (13), Availability of participants (14), Availability of medical instruments (15), Expertise in neurosciences (16), Requirement of business academicians (17), Awareness about techniques used (18), Tracking of unidentified consumer needs (19), Increasing awareness among marketers (20), Adopting relevant new technology (21), Company tie-ups and sponsorships (22), Obtaining free will of participants (23), Training and development of employees (24), Getting ample number of participants for experimentation (25), Tapping the felt need for new technology (26), Trust of research firms and consumers (27). For the analysis of these variables, the contextual relationship of affect is chosen which means that one variable affects the other in one way or the other. Further, since there is a contextual relationship existing between two variables ( $i$ and $j$ ), the direction of their association is determined. Four symbols are used to determine the type of relation that exists between two variables that are considered: $\mathrm{V}$ - variable $\mathrm{i}$ affects variable $\mathrm{j}$; $\mathrm{A}$ - variable $\mathrm{j}$ affects variable $\mathrm{i}$; $\mathrm{X}$ - variables $\mathrm{i}$ and $\mathrm{j}$ affect each other; $\mathrm{O}$ - variables $\mathrm{j}$ and $\mathrm{i}$ are unrelated. Based on these, an SSIM is prepared which is shown in Table 1 below:

\begin{tabular}{|c|c|c|c|c|c|c|c|c|c|c|c|c|c|c|c|c|c|c|c|c|c|c|c|c|c|c|c|}
\hline Ylieneat & 27 & 26 & 23 & 34 & 12 & 32 & 21 & 20 & 10 & 18 & 17 & 16 & 19 & ${ }^{14}$ & 21 & 12 & 12 & 10 & 2 & 8 & 7 & 8 & $=$ & & 4 & 3 & 2 \\
\hline 1 & V & 0 & 0 & A & A & 0 & A & A & $\mathrm{V}$ & A & A & A & A & A & A & 0 & A & A & 0 & $\mathrm{~V}$ & $\mathrm{~V}$ & $\mathrm{v}$ & $v$ & & $\mathrm{~V}$ & A & 0 \\
\hline 2 & $\mathrm{v}$ & 0 & 0 & $A$ & 0 & 0 & $A$ & 0 & A & 0 & 0 & 0 & 0 & 0 & 0 & 0 & 0 & 0 & 0 & 0 & $\mathrm{~V}$ & $x$ & $A$ & & A & $A$ & \\
\hline 3 & $\mathrm{v}$ & $\mathrm{v}$ & $A$ & $A$ & 0 & 0 & A & 0 & $\mathrm{~V}$ & 0 & A & A & A & A & A & 0 & $\bar{A}$ & A & 0 & $\bar{x}$ & $\mathrm{~V}$ & $\vec{v}$ & $\sqrt{2}$ & & $\mathrm{~V}$ & & \\
\hline 4 & $\mathrm{~V}$ & $\mathrm{~V}$ & 0 & $A$ & 0 & $\mathrm{~A}$ & A & $A$ & A & 0 & A & 0 & 0 & A & A & A & A & A & $A$ & A & $\mathrm{V}$ & $x$ & $v$ & & & & \\
\hline 5 & $\mathrm{v}$ & $\mathrm{V}$ & 0 & 0 & 0 & 0 & A & $A$ & A & 0 & $A$ & 0 & 0 & 0 & 0 & 0 & A & 0 & 0 & 0 & $\mathrm{~V}$ & $\vec{v}$ & & & & & \\
\hline 6 & $\mathrm{~V}$ & $\mathrm{~V}$ & 0 & 0 & 0 & $\mathrm{~A}$ & A & A & A & $A$ & A & 0 & 0 & 0 & A & A & A & 0 & 0 & 0 & $x$ & & & & & & \\
\hline 7 & $\mathrm{v}$ & $\mathrm{v}$ & 0 & $A$ & 0 & $\mathrm{~A}$ & $\bar{x}$ & 0 & A & 0 & 0 & 0 & 0 & 0 & $\bar{x}$ & 0 & 0 & A & $A$ & 0 & & & & & & & \\
\hline 8 & 0 & $\mathrm{~V}$ & 0 & $A$ & 0 & $\mathrm{~V}$ & A & $\mathrm{V}$ & 0 & 0 & A & $A$ & A & $\mathrm{A}$ & 0 & A & $\bar{A}$ & A & 0 & & & & & & & & \\
\hline 9 & $x$ & 0 & $\mathrm{~V}$ & 0 & $A$ & 0 & 0 & $\mathrm{v}$ & $\mathrm{x}$ & $A$ & 0 & 0 & 0 & 0 & 0 & A & A & $\mathrm{A}$ & & & & & & & & & \\
\hline 10 & $x$ & 0 & $\mathrm{~V}$ & $\mathrm{~V}$ & $\mathrm{~V}$ & $\mathrm{~V}$ & $\mathrm{~V}$ & 0 & 0 & $x$ & A & A & A & A & 0 & A & A & & & & & & & & & & \\
\hline 11 & $\mathrm{~V}$ & 0 & $\mathrm{v}$ & $\mathrm{V}$ & 0 & $\mathrm{~V}$ & $\mathrm{v}$ & $\mathrm{v}$ & $\mathrm{V}$ & $\mathrm{V}$ & A & $A$ & A & $\mathrm{A}$ & A & A & & & & & & & & & & & \\
\hline 12 & $\mathrm{~V}$ & 0 & $\mathrm{~V}$ & $\mathrm{v}$ & $\mathrm{V}$ & $\mathrm{V}$ & $\mathrm{v}$ & $\mathrm{v}$ & $\mathrm{V}$ & $\mathrm{v}$ & 0 & 0 & 0 & 0 & 0 & & & & & & & & & & & & \\
\hline 13 & 0 & 0 & $\mathrm{v}$ & $\mathrm{v}$ & $\mathrm{v}$ & A & $\mathrm{V}$ & $\mathrm{v}$ & 0 & 0 & $\mathrm{~V}$ & $\mathrm{~V}$ & $\mathrm{~V}$ & $\mathrm{~V}$ & & & & & & & & & & & & & \\
\hline 14 & 0 & 0 & $A$ & 0 & $A$ & $A$ & 0 & A & $\mathrm{V}$ & $A$ & 0 & 0 & 0 & & & & & & & & & & & & & & \\
\hline 15 & 0 & 0 & 0 & $\mathrm{v}$ & 0 & 0 & $\mathrm{~V}$ & 0 & 0 & 0 & 0 & 0 & & & & & & & & & & & & & & & \\
\hline 16 & $\mathrm{v}$ & $\mathrm{v}$ & 0 & 0 & 0 & $\mathrm{v}$ & $\mathrm{V}$ & A & $\mathrm{V}$ & 0 & 0 & & & & & & & & & & & & & & & & \\
\hline 17 & $\mathrm{~V}$ & $\mathrm{~V}$ & 0 & 0 & 0 & $\mathrm{~V}$ & $\mathrm{v}$ & $x$ & $\mathrm{~V}$ & 0 & & & & & & & & & & & & & & & & & \\
\hline 18 & $\mathrm{v}$ & $\mathrm{v}$ & $\mathrm{v}$ & 0 & $\mathrm{v}$ & $x$ & $\mathrm{v}$ & $\mathrm{v}$ & $\mathrm{V}$ & & & & & & & & & & & & & & & & & & \\
\hline 19 & $\mathrm{~V}$ & $\mathrm{~V}$ & A & 0 & A & 0 & A & A & & & & & & & & & & & & & & & & & & & \\
\hline 20 & $x$ & $A$ & $\mathrm{v}$ & $A$ & $\mathrm{v}$ & $\mathrm{V}$ & $\mathrm{v}$ & & & & & & & & & & & & & & & & & & & & \\
\hline 21 & $A$ & A & $\mathrm{v}$ & $\mathrm{v}$ & $\mathrm{v}$ & $x$ & & & & & & & & & & & & & & & & & & & & & \\
\hline 22 & $A$ & $A$ & $\mathrm{v}$ & $\mathrm{v}$ & $\mathrm{V}$ & & & & & & & & & & & & & & & & & & & & & & \\
\hline 23 & $A$ & $A$ & $x$ & $A$ & & & & & & & & & & & & & & & & & & & & & & & \\
\hline 24 & $A$ & $A$ & 0 & & & & & & & & & & & & & & & & & & & & & & & & \\
\hline 25 & A & A & & & & & & & & & & & & & & & & & & & & & & & & & \\
\hline 26 & 0 & & & & & & & & & & & & & & & & & & & & & & & & & & \\
\hline
\end{tabular}

\section{Reachability Matrix}

The SSIM table is now transformed into a reachability matrix by converting the value in each cell in ' 0 's and 1's based on the following situations: If $(i, j)$ entry is $V$, then $(i, j)$ in reachability matrix becomes 1 and $(j, i)$ entries is 0 . If $(i, j)$ entry is $A$, then $(i, j)$ in reachability matrix becomes 0 and $(j, i)$ entries is 1 . If $(i, j)$ entry is $X$, then $(i, j)$ in reachability matrix becomes 1 and $(\mathrm{j}, \mathrm{i})$ entries is 1 . If $(\mathrm{i}, \mathrm{j})$ entry is $\mathrm{O}$, then $(\mathrm{i}, \mathrm{j})$ in reachability matrix becomes 0 
Further, ' $1 *$ ' is incorporated depicting transitivity which aims to fill in any gap in the opinion that is collected during the brainstorming sessions. Table III shows the final reachability matri

Table II Initial Reachability Matrixx.

\begin{tabular}{|c|c|c|c|c|c|c|c|c|c|c|c|c|c|c|c|c|c|c|c|c|c|c|c|c|c|c|c|}
\hline $\mathrm{naman}$ & 2 & 2 & 7 & 2 & 3 & $*$ & 7 & 8 & 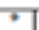 & 56 & 4 & 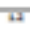 & 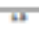 & 25 & 3 & 6 & 35 & $\pi$ & 6 & 20 & 21 & 21 & 2 & $2 x$ & 23 & $2 \pi$ & 25 \\
\hline 1 & 1 & 0 & 0 & 1 & 1 & 1 & 1 & 1 & 0 & 0 & 0 & 0 & 0 & 0 & 0 & 0 & 0 & 0 & 1 & 0 & 0 & 0 & 0 & 0 & 0 & 0 & 1 \\
\hline 3 & 1 & 1 & 1 & 1 & 1 & 1 & 1 & 1 & 0 & 0 & 0 & 0 & 0 & 0 & 0 & 0 & 0 & 0 & 1 & 0 & 0 & 0 & 0 & 0 & 0 & 1 & 1 \\
\hline 4 & 0 & 1 & 0 & 1 & 1 & 1 & 1 & 0 & 0 & 0 & 0 & 0 & 0 & 0 & 0 & 0 & 0 & 0 & 0 & 0 & 0 & 0 & 0 & 0 & 0 & 1 & 1 \\
\hline 6 & 0 & 1 & 0 & 1 & 0 & 1 & 1 & 0 & 0 & 0 & 0 & 0 & 0 & 0 & 0 & 0 & 0 & 0 & 0 & 0 & 0 & 0 & 0 & 0 & 0 & 1 & 1 \\
\hline 7 & 0 & 0 & 0 & 0 & 0 & 1 & 1 & 0 & 0 & 0 & 0 & 0 & 1 & 0 & 0 & 0 & 0 & 0 & 0 & 0 & 1 & 0 & 0 & 0 & 0 & 1 & 1 \\
\hline 8 & 0 & 0 & 1 & 1 & 0 & 0 & 0 & 1 & 0 & 0 & 0 & 0 & 0 & 0 & 0 & 0 & 0 & 0 & 0 & 1 & 0 & 1 & 0 & 0 & 0 & 1 & 0 \\
\hline 11 & 1 & 0 & 1 & 1 & 1 & 1 & 0 & 1 & 1 & 1 & 1 & 0 & 0 & 0 & 0 & 0 & 0 & 1 & 1 & 1 & 1 & 1 & 0 & 1 & 1 & 0 & 1 \\
\hline 12 & 0 & 0 & 0 & 1 & 0 & 1 & 0 & 1 & 1 & 1 & 1 & 1 & 0 & 0 & 0 & 0 & 0 & 1 & 1 & 1 & 1 & 1 & 1 & 1 & 1 & 0 & 1 \\
\hline 13 & 1 & 0 & 1 & 1 & 0 & 1 & 1 & 0 & 0 & 0 & 1 & 0 & 1 & 1 & 1 & 1 & 1 & 0 & 0 & 1 & 1 & 0 & 1 & 1 & 1 & 0 & 0 \\
\hline 14 & 1 & 0 & 1 & 1 & 0 & 0 & 0 & 1 & 0 & 1 & 1 & 0 & 0 & 1 & 0 & 0 & 0 & 0 & 1 & 0 & 0 & 0 & 0 & 0 & 0 & 0 & 0 \\
\hline 15 & 1 & 0 & 1 & 0 & 0 & 0 & 0 & 1 & 0 & 1 & 1 & 0 & 0 & 0 & 1 & 0 & 0 & 0 & 0 & 0 & 1 & 0 & 0 & 1 & 0 & 0 & 0 \\
\hline 16 & 1 & 0 & 1 & 0 & 0 & 0 & 0 & 1 & 0 & 1 & 1 & 0 & 0 & 0 & 0 & 1 & 0 & 0 & 1 & 0 & 1 & 1 & 0 & 0 & 0 & 1 & 1 \\
\hline 17 & 1 & 0 & 1 & 1 & 1 & 1 & 0 & 1 & 0 & 1 & 1 & 0 & 0 & 0 & 0 & 0 & 1 & 0 & 1 & 1 & 1 & 1 & 0 & 0 & 0 & 1 & 1 \\
\hline 23 & 1 & 0 & 0 & 0 & 0 & 0 & 0 & 0 & 1 & 0 & 0 & 0 & 0 & 1 & 0 & 0 & 0 & 0 & 1 & 0 & 0 & 0 & 1 & 0 & 1 & 0 & 0 \\
\hline 24 & 1 & 1 & 1 & 1 & 0 & 0 & 1 & 1 & 0 & 0 & 0 & 0 & 0 & 0 & 0 & 0 & 0 & 0 & 0 & 1 & 0 & 0 & 1 & 1 & 0 & 0 & 0 \\
\hline 25 & 0 & 0 & 1 & 0 & 0 & 0 & 0 & 0 & 0 & 0 & 0 & 0 & 0 & 1 & 0 & 0 & 0 & 0 & 1 & 0 & 0 & 0 & 1 & 0 & 1 & 0 & 0 \\
\hline 26 & 0 & 0 & 0 & 0 & 0 & 0 & 0 & 0 & 0 & 0 & 0 & 0 & 0 & 0 & 0 & 0 & 0 & 0 & 0 & 1 & 1 & 1 & 1 & 1 & 1 & 1 & 0 \\
\hline 27 & 0 & 0 & 0 & 0 & 0 & 0 & 0 & 0 & 1 & 1 & 0 & 0 & 0 & 0 & 0 & 0 & 0 & 0 & 0 & 1 & 1 & 1 & 1 & 1 & 1 & 0 & 1 \\
\hline
\end{tabular}

Table III Final Reachability Matrix

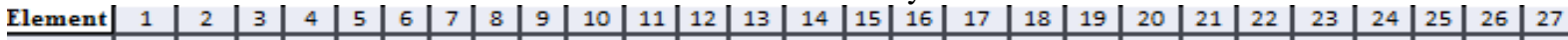
\begin{tabular}{c|c|c|c|c|c|c|c|c|c|c|c|c|c|c|c|c|c|c|c|c|c|c|c|c|c|c|c|}
\hline 1 & 1 & $\mathbf{1}^{*}$ & $\mathbf{1}^{*}$ & 1 & 1 & 1 & 1 & 1 & $\mathbf{1}^{*}$ & $\mathbf{1}^{*}$ & 0 & 0 & $\mathbf{1}^{*}$ & 0 & 0 & 0 & 0 & 0 & 1 & $\mathbf{1}^{*}$ & $\mathbf{1}^{*}$ & $\mathbf{1}^{*}$ & $\mathbf{1}^{*}$ & $\mathbf{1}^{*}$ & $\mathbf{1}^{*}$ & $\mathbf{1}^{*}$ & $\mathbf{1}^{1}$ \\
\hline
\end{tabular} \begin{tabular}{c|c|c|c|c|c|c|c|c|c|c|c|c|c|c|c|c|c|c|c|c|c|c|c|c|c|c|c}
\hline 2 & $1^{*}$ & 1 & 0 & $1^{*}$ & 0 & 1 & 1 & 0 & $1^{*}$ & $1^{*}$ & 0 & 0 & $1^{*}$ & 0 & 0 & 0 & 0 & 0 & 0 & $1^{*}$ & $1^{*}$ & $1^{*}$ & $1^{*}$ & $1^{*}$ & $1^{*}$ & $1^{*}$ & 1 \\
\hline
\end{tabular}

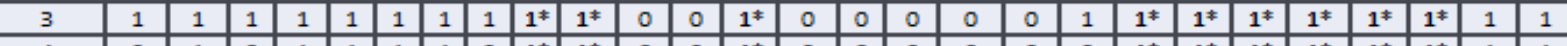

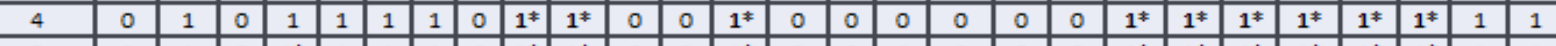

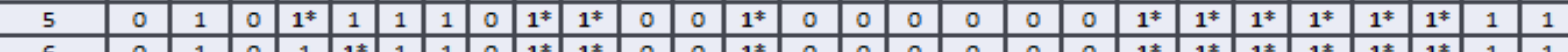
\begin{tabular}{l|l|l|l|l|l|l|l|l|l|l|l|l|l|l|l|l|l|l|l|l|l|l|l|l|l|l}
\hline 6 & 0 & 1 & 0 & 1 & $\mathbf{1}^{*}$ & 1 & 1 & 0 & $\mathbf{1}^{*}$ & $\mathbf{1}^{*}$ & 0 & 0 & $\mathbf{1}^{*}$ & 0 & 0 & 0 & 0 & 0 & 0 & $\mathbf{1}^{*}$ & $\mathbf{1}^{*}$ & $\mathbf{1}^{*}$ & $\mathbf{1}^{*}$ & $\mathbf{1}^{*}$ & $\mathbf{1}^{*}$ & 1 \\
\hline
\end{tabular}

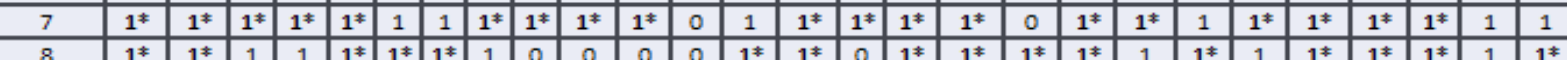

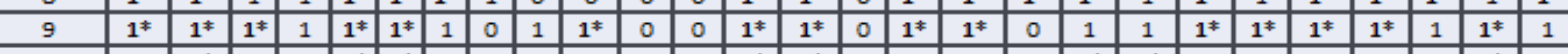
\begin{tabular}{c|c|c|c|c|c|c|c|c|c|c|c|c|c|c|c|c|c|c|c|c|c|c|c|c|c|c|c}
\hline 10 & 1 & $\mathbf{1}^{*}$ & 1 & 1 & $\mathbf{1}^{*}$ & $\mathbf{1}^{*}$ & 1 & 1 & 1 & 1 & 0 & 0 & $\mathbf{1}^{*}$ & $\mathbf{1}^{*}$ & 0 & 0 & 0 & 1 & $\mathbf{1}^{*}$ & $\mathbf{1}^{*}$ & 1 & 1 & 1 & 1 & 1 & $\mathbf{1}^{*}$ & 1 \\
\hline
\end{tabular} \begin{tabular}{l|c|c|c|c|c|c|c|c|c|c|c|c|c|c|c|c|c|c|c|c|c|c|c|c|c|c|c}
\hline 11 & 1 & $\mathbf{1}^{*}$ & 1 & 1 & 1 & 1 & $\mathbf{1}^{*}$ & 1 & 1 & 1 & 1 & 0 & $\mathbf{1}^{*}$ & $\mathbf{1}^{*}$ & 0 & $\mathbf{1}^{*}$ & $\mathbf{1}^{*}$ & 1 & 1 & 1 & 1 & 1 & $\mathbf{1}^{*}$ & 1 & 1 & $\mathbf{1}^{*}$ & 1 \\
\hline
\end{tabular} \begin{tabular}{l|l|l|l|l|l|l|l|l|l|l|l|l|l|l|l|l|l|l|l|l|l|l|l|l|l|l|l}
\hline 12 & $\mathbf{1}^{*}$ & $\mathbf{1}^{*}$ & $\mathbf{1}^{*}$ & 1 & $\mathbf{1}^{*}$ & 1 & $\mathbf{1}^{*}$ & 1 & 1 & 1 & 1 & 1 & $\mathbf{1}^{*}$ & $\mathbf{1}^{*}$ & 0 & $\mathbf{1}^{*}$ & $\mathbf{1}^{*}$ & 1 & 1 & 1 & 1 & 1 & 1 & 1 & 1 & $\mathbf{1}^{*}$ & 1 \\
\hline
\end{tabular} \begin{tabular}{l|l|l|l|l|l|l|l|l|l|l|l|l|l|l|l|l|l|l|l|l|l|l|l|l|l|l|l}
\hline 13 & 1 & $\mathbf{1}^{*}$ & 1 & 1 & $\mathbf{1}^{*}$ & 1 & 1 & $\mathbf{1}^{*}$ & $\mathbf{1}^{*}$ & $\mathbf{1}^{*}$ & $\mathbf{1}$ & 0 & 1 & 1 & 1 & 1 & 1 & $\mathbf{1}^{*}$ & $\mathbf{1}^{*}$ & $\mathbf{1}$ & $\mathbf{1}$ & $\mathbf{1}^{*}$ & 1 & 1 & 1 & $\mathbf{1}^{*}$ & $\mathbf{1}^{*}$ \\
\hline
\end{tabular}

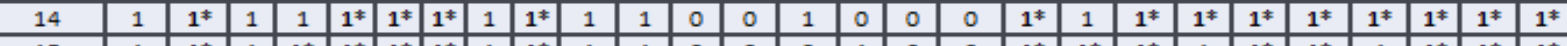

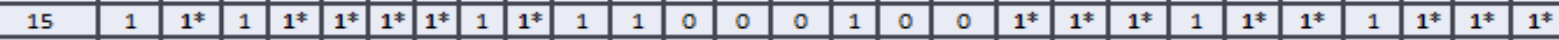
\begin{tabular}{c|c|c|c|c|c|c|c|c|c|c|c|c|c|c|c|c|c|c|c|c|c|c|c|c|c|c|c|}
\hline 16 & 1 & $\mathbf{1}^{*}$ & 1 & $\mathbf{1}^{*}$ & $\mathbf{1}^{*}$ & $\mathbf{1}^{*}$ & $\mathbf{1}^{*}$ & 1 & $\mathbf{1}^{*}$ & 1 & 1 & 0 & $\mathbf{1}^{*}$ & $\mathbf{1}^{*}$ & 0 & 1 & 0 & $\mathbf{1}^{*}$ & 1 & $\mathbf{1}^{*}$ & 1 & 1 & $\mathbf{1}^{*}$ & $\mathbf{1}^{*}$ & $\mathbf{1}^{*}$ & 1 & $1^{*}$ \\
\hline
\end{tabular} \begin{tabular}{l|l|l|l|l|l|l|l|l|l|l|l|l|l|l|l|l|l|l|l|l|l|l|l|l|l|l|l} 
& 1 \\
\hline 17 & 1 & $\mathbf{1}^{*}$ & 1 & 1 & 1 & 1 & $\mathbf{1}^{*}$ & 1 & $\mathbf{1}^{*}$ & $\mathbf{1}$ & $\mathbf{1}$ & 0 & $\mathbf{1}^{*}$ & $\mathbf{1}^{*}$ & 0 & $\mathbf{1}^{*}$ & 1 & $\mathbf{1}^{*}$ & 1 & 1 & 1 & 1 & $\mathbf{1}^{*}$ & $\mathbf{1}^{*}$ & $\mathbf{1}^{*}$ & 1 & 1 \\
\hline
\end{tabular} \begin{tabular}{l|l|l|l|l|l|l|l|l|l|l|l|l|l|l|l|l|l|l|l|l|l|l|l|l|l|l|l}
\hline 18 & 1 & $1^{*}$ & $1^{*}$ & $\mathbf{1}^{*}$ & $\mathbf{1}^{*}$ & 1 & $\mathbf{1}^{*}$ & $\mathbf{1}^{*}$ & 1 & 1 & $\mathbf{1}^{*}$ & 0 & $\mathbf{1}^{*}$ & 1 & 0 & $\mathbf{1}^{*}$ & $\mathbf{1}^{*}$ & 1 & 1 & 1 & 1 & 1 & 1 & $\mathbf{1}^{*}$ & 1 & 1 & 1 \\
\hline
\end{tabular} \begin{tabular}{l|l|l|l|l|l|l|l|l|l|l|l|l|l|l|l|l|l|l|l|l|l|l|l|l|l|l|l}
\hline 19 & 0 & 1 & 0 & 1 & 1 & 1 & 1 & 0 & 1 & $\mathbf{1}^{*}$ & 0 & 0 & $\mathbf{1}^{*}$ & 0 & 0 & 0 & 0 & 0 & 1 & $\mathbf{1}^{*}$ & $\mathbf{1}^{*}$ & $\mathbf{1}^{*}$ & $\mathbf{1}^{*}$ & $\mathbf{1}^{*}$ & $\mathbf{1}^{*}$ & 1 & 1 \\
\hline
\end{tabular} \begin{tabular}{c|c|c|c|c|c|c|c|c|c|c|c|c|c|c|c|c|c|c|c|c|c|c|c|c|c|c|c|}
\hline 20 & 1 & $\mathbf{1}^{*}$ & $\mathbf{1}^{*}$ & 1 & 1 & 1 & $\mathbf{1}^{*}$ & $\mathbf{1}^{*}$ & $\mathbf{1}^{*}$ & $\mathbf{1}^{*}$ & $\mathbf{1}^{*}$ & 0 & $\mathbf{1}^{*}$ & $\mathbf{1}$ & 0 & 1 & 1 & $\mathbf{1}^{*}$ & 1 & 1 & 1 & 1 & 1 & $\mathbf{1}^{*}$ & 1 & $\mathbf{1}^{*}$ & 1 \\
\hline
\end{tabular} \begin{tabular}{l|c|c|c|c|c|c|c|c|c|c|c|c|c|c|c|c|c|c|c|c|c|c|c|c|c|c|c}
\hline 21 & 1 & 1 & 1 & 1 & 1 & 1 & 1 & 1 & $\mathbf{1}^{*}$ & 0 & 0 & 0 & $\mathbf{1}^{*}$ & $\mathbf{1}^{*}$ & 0 & 0 & 0 & $\mathbf{1}^{*}$ & 1 & $\mathbf{1}^{*}$ & 1 & 1 & 1 & 1 & 1 & $\mathbf{1}^{*}$ & $\mathbf{1}^{*}$ \\
\hline
\end{tabular} \begin{tabular}{l|c|c|c|c|c|c|c|c|c|c|c|c|c|c|c|c|c|c|c|c|c|c|c|c|c|c|c|}
\hline 22 & $1^{*}$ & $1^{*}$ & $1^{*}$ & 1 & $1^{*}$ & 1 & 1 & $1^{*}$ & $1^{*}$ & $1^{*}$ & $1^{*}$ & 0 & 1 & 1 & $1^{*}$ & $1^{*}$ & $1^{*}$ & 1 & $1^{*}$ & $1^{*}$ & 1 & 1 & 1 & 1 & 1 & $1^{*}$ & $1^{*}$ \\
\hline
\end{tabular}

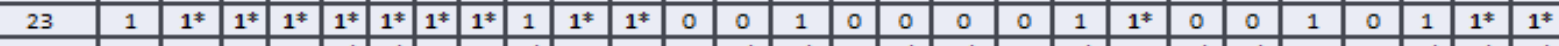
\begin{tabular}{|l|c|c|c|c|c|c|c|c|c|c|c|c|c|c|c|c|c|c|c|c|c|c|c|c|c|c|c|}
24 & 1 & 1 & 1 & 1 & $\mathbf{1}^{*}$ & $\mathbf{1}^{*}$ & 1 & 1 & $\mathbf{1}^{*}$ & 0 & 0 & 0 & $\mathbf{1}^{*}$ & $\mathbf{1}^{*}$ & 0 & $\mathbf{1}^{*}$ & $\mathbf{1}^{*}$ & 0 & $\mathbf{1}^{*}$ & $\mathbf{1}$ & $\mathbf{1}^{*}$ & $\mathbf{1}^{*}$ & 1 & 1 & $\mathbf{1}^{*}$ & $\mathbf{1}^{*}$ & $\mathbf{1}^{*}$ \\
\hline
\end{tabular}

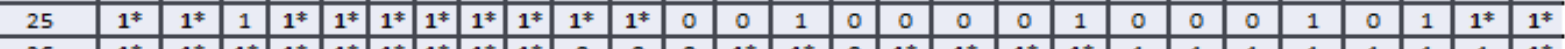

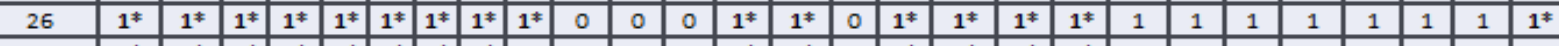

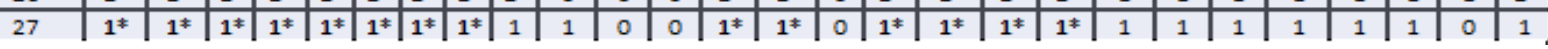

\section{Partitioning the reachability matrix}

The reachability matrix is partitioned with the help of identification of antecedent and reachability sets for every variable. The reachability set consists of element which directly affects whereas antecedent set consists of elements which may be affected. Then the intersection set is derived from these sets for all the elements. The elements for which the reachability set and intersection set are same act as the top level elements in ISM model. Once these are found, they are separated. This process is repeated until all the iterations are complete and all intersections are obtained. All the iterations for this procedure are shown below. 
Table IV. Iteration 1

\begin{tabular}{|c|c|c|c|}
\hline REACHABLLTTY SET (Pi) & ANTECEDENT SET (Pj) & INTERSECTION & LEVEL \\
\hline $11,2,3,4,5,5,6,7,8,9,1,10,13,19,20,211,22,23,24,25,26,27$ & $1,2,3,7,7,9,9,10,11,12,13,14,15,16,17,18,20,21,22,23,24,25,26,27$ & $1,2,3,7,7,8,9,10,13,20,21,22,23,24,25,26,27$ & \\
\hline $21,2,4,6,7,9,10,13,20,21,222,23,24,25,26,27$ & $1,23,4,4,6,6,7,8,9,10,11,12,13,14,15,16,17,18,19,20,21,22,23,24,25,26,2:$ & $2 ; 1,24,4,6,7,9,10,13,20,21,22,23,24,25,26,27$ & I \\
\hline $31,2,3,4,5,5,6,7,7,9,9,10,13,19,20,21,22,23,24,25,26,27$ & $1,3,7,7,9,9,10,11,12,13,14,15,16,17,18,20,21,22,23,24,25,26,27$ & $1,3,7,8,9,9,10,13,20,21,22,23,24,25,26,27$ & \\
\hline $42,4,5,6,7,9,10,13,20,21,222,23,24,25,26,27$ & 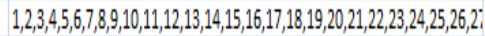 & $2 ; 24,4,5,6,7,9,10,13,13,20,21,22,23,24,25,26,27$ & I \\
\hline $52,4,5,6,7,9,1,10,13,20,21,22,23,24,25,26,27$ & $1,3,4,4,5,6,7,8,9,10,111,12,13,14,15,16,17,18,19,20,21,22,23,24,25,26,27$ & $4,5,5,7,7,9,10,13,20,21,22,23,24,25,26,27$ & \\
\hline $62,4,5,6,6,7,9,10,13,20,21,22,23,24,25,26,27$ & $1,2,3,4,4,5,6,7,7,9,9,10,11,12,13,14,15,16,17,18,19,20,21,22,23,24,25,26,2 i$ & $222,4,5,6,7,7,9,10,13,20,21,22,23,24,25,26,27$ & I \\
\hline $71,2,3,4,4,5,6,7,8,9,10,111,13,14,15,16,17,19,20,21,22,23,24,25,26,27$ & 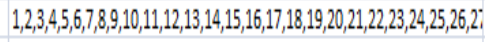 & $2: 1,2,3,4,4,5,6,7,8,9,1,10,11,13,14,15,15,16,17,19,20,21,22,23,24,25,26,27$ & 71 \\
\hline $81,2,3,4,5,6,6,7,8,13,14,16,17,18,19,20,21,22,23,24,25,26,27$ & $1,3,7,8,10,11,112,13,14,15,16,17,188,20,21,22,23,24,25,26,27$ & $1,3,7,7,13,13,14,16,17,18,20,21,22,23,24,25,26,27$ & \\
\hline $91,2,3,4,5,5,6,7,9,10,13,14,16,17,19,20,21,22,23,24,25,26,27$ & $1,23,3,4,5,6,7,9,10,10,11,12,13,14,15,16,16,17,18,19,20,21,22,23,24,25,26,27$ & $1,2,3,4,5,6,7,7,9,10,13,14,16,17,19,20,21,22,23,24,25,26,27$ & 1 \\
\hline $101,2,3,4,5,5,6,7,7,9,9,10,13,14,18,19,20,21,22,23,24,25,26,27$ & $1,2,3,4,5,5,6,7,9,10,11,12,13,14,15,16,17,18,19,20,22,23,25,27$ & $1,2,3,4,5,6,7,7,9,10,13,14,18,19,20,22,23,25,27$ & \\
\hline $111,1,2,3,4,5,6,6,7,8,9,10,111,13,14,16,17,18,19,20,21,22,23,24,25,26,27$ & $7,11,12,13,14,15,16,17,18,20,22,23,25$ & $7,11,13,14,16,17,18,20,22,23,25$ & \\
\hline $121,2,3,4,4,5,6,7,7,8,9,10,11,12,13,14,16,17,18,19,20,21,22,23,24,25,26,27$ & 712 & 12 & \\
\hline $131,2,3,4,5,5,6,7,7,9,9,10,11,13,14,15,16,17,18,19,20,21,22,23,24,25,26,27$ & $7,2,2,4,4,5,6,7,7,9,9,10,11,12,13,16,17,18,19,20,21,22,24,26,27$ & $1,2,3,4,5,6,7,7,8,9,10,11,13,16,17,18,19,20,21,22,24,26,27$ & \\
\hline $141,2,3,4,5,5,6,7,7,9,1,10,11,14,18,19,20,21,22,23,24,25,26,27$ & $7,8,9,10,111,12,13,14,16,17,18,20,21,22,23,24,25,26,27$ & $7,8,9,10,11,14,18,20,21,22,23,24,25,26,27$ & \\
\hline $151,2,2,4,4,5,6,7,7,9,1,10,111,15,18,19,20,21,22,23,24,25,26,27$ & $7,13,15,22$ & $7,15,22$ & \\
\hline $161,2,3,4,4,5,6,7,7,9,9,10,111,13,14,16,18,19,20,21,22,23,24,25,26,27$ & $7,8,9,111,12,13,16,17,18,20,22,24,26,27$ & $7,8,9,11,13,16,18,20,22,24,26,27$ & \\
\hline $171,2,3,4,5,5,6,7,8,9,10,11,13,14,16,17,18,19,20,21,22,23,24,25,26,27$ & $7,8,9,11,12,13,17,18,20,22,24,26,27$ & $7,8,9,11,13,17,18,20,22,24,26,27$ & \\
\hline 18 1,2,3,4,4,5,6,7,8,9,9,10,11,13,14,16,17,17,18,19,20,21,22,23,24,25,26,27 & $8,10,11,12,13,14,15,16,17,18,20,21,22,26,27$ & $8,10,11,13,14,16,17,18,20,21,22,26,27$ & \\
\hline $192,4,5,6,6,7,9,10,13,19,20,21,22,23,24,25,26,27$ & $1,3,7,7,9,10,111,12,13,14,15,16,17,18,19,20,21,22,23,24,25,26,27$ & $7,9,10,13,19,20,21,22,23,24,25,26,27$ & \\
\hline $201,2,3,4,5,5,6,7,8,9,10,10,11,13,14,16,17,18,19,20,21,22,23,24,25,26,27$ & $1,2,3,4,4,5,6,7,8,9,9,10,11,12,13,14,15,16,17,18,19,20,21,22,23,24,26,27$ & $1,2,3,4,4,5,6,7,7,8,9,10,11,13,14,16,17,18,19,20,21,22,23,24,26,27$ & \\
\hline $211,2,3,4,4,5,6,7,8,9,9,13,14,18,19,20,21,22,23,24,25,26,27$ & $1,2,3,4,4,5,6,7,8,9,9,10,11,12,13,14,15,16,17,18,19,20,21,22,24,26,27$ & $1,2,3,4,4,5,6,7,7,9,9,13,14,18,19,20,21,22,24,26,27$ & \\
\hline $221,2,3,4,5,5,6,7,7,9,9,10,11,13,14,15,16,16,17,18,19,20,21,22,23,24,25,26,27$ & $71,2,3,4,5,6,6,7,8,9,10,11,12,13,14,15,16,17,18,19,20,21,22,24,26,27$ & $1,2,3,4,5,5,6,7,8,9,9,10,11,13,14,15,16,17,18,19,20,21,22,24,26,27$ & \\
\hline $231,2,3,4,5,6,6,7,8,9,10,11,14,19,20,23,25,26,27$ & 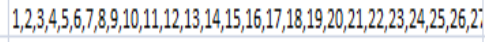 & $2: 1,2,3,4,5,5,6,7,8,9,10,11,14,19,20,23,25,26,27$ & I \\
\hline $241,2,3,4,5,5,7,7,8,9,13,14,16,16,17,19,20,21,22,23,24,25,26,27$ & $1,2,3,4,5,6,7,7,8,9,10,11,12,13,14,15,16,17,18,19,20,21,22,24,26,27$ & $1,2,3,4,5,5,6,7,8,9,13,14,14,16,17,19,20,21,22,24,26,27$ & \\
\hline $251,2,3,4,5,5,6,7,8,9,9,10,11,14,19,23,25,26,27$ & $1,2,3,4,4,5,6,7,8,9,9,10,11,12,13,14,15,16,17,18,19,20,21,22,23,24,25,26,2 i$ & $2 ; 1,2,3,4,4,5,6,7,7,9,9,10,11,14,19,23,25,26,27$ & I \\
\hline $261,2,3,4,5,5,6,7,7,9,9,13,14,16,17,18,19,20,21,22,23,24,25,26,27$ & $1,2,3,4,5,6,6,7,8,9,1,10,11,12,13,14,15,16,17,18,19,20,21,22,23,24,25,26$ & $1,2,3,4,4,5,6,7,7,9,9,13,14,16,17,18,19,20,21,22,23,24,25,26$ & \\
\hline $271,2,3,4,4,6,7,7,8,9,10,13,14,16,17,18,19,20,21,22,23,24,25,27$ & 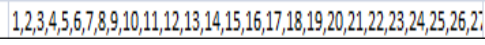 & $2: 1,2,3,4,5,5,7,7,8,9,10,13,14,16,17,18,19,20,21,22,23,24,25,27$ & I \\
\hline
\end{tabular}

Table V. Iteration 2

\begin{tabular}{|c|c|c|c|}
\hline ELEMENT REACHABULITY SET (Pi) & ANTECEDENT SET (Pי.) & INTERSECTION & \\
\hline $11,3,5,8,8,10,13,19,20,21,22,24,26$ & $1,3,8,10,10,11,12,13,13,14,15,16,17,18,20,20,21,22,2,24,26$ & $1,3,8,10,13,20,21,22,24,26$ & \\
\hline $31,3,5,5,8,10,13,19,20,21,22,24,26$ & $1,3,8,10,11,12,12,13,14,15,16,17,1,18,20,2121,22,24,26$ & $1,3,8,10,13,20,21,22,24,26$ & \\
\hline $55,100,13,20,212,22,24,26$ & $1,3,4,5,8,10,10,11,12,12,13,14,15,16,16,17,18,19,20,21,22,24,26$ & $5,10,13,20,212,22,24,26$ & $\|$ \\
\hline $81,3,5,8,8,13,14,16,17,18,1,19,20,21,2,22,24,26$ & $1,3,8,10,11,12,12,13,14,15,16,17,17,18,20,21,22,2,24,26$ & $1,3,8,1,13,1,1,16,17,1,18,20,21,22,2,2,2,26$ & \\
\hline $101,3,5,5,8,10,13,1,14,18,19,20,21,22,24,24,26$ & $1,3,5,10,11,12,12,13,14,15,15,16,17,1,18,19,20,22,22$ & $1,3,5,10,10,13,14,18,19,2,20,22,23$ & \\
\hline $111,3,5,5,8,10,11,13,14,16,17,18,19,20,21,22,24,26$ & $11,12,13,14,15,16,16,17,18,20,22$ & $11,13,14,16,17,18,20,22,22$ & \\
\hline $121,3,5,8,10,10,11,12,12,13,14,16,16,17,18,19,20,212,22,24,26$ & 12 & 12 & \\
\hline $131,1,3,5,8,10,10,11,13,1,14,15,16,17,17,18,19,20,21,22,22,4,26$ & $1,3,5,5,10,10,11,12,12,13,16,17,1,18,19,20,21,2,22,24,26$ & $1,3,5,8,10,0,11,13,1,16,17,18,19,29,20,21,22,24,4,26$ & \\
\hline $141,3,5,5,8,10,111,14,18,19,20,21,222,24,26$ & $8,10,11,12,13,14,14,16,17,18,20,21,22,24,26,26$ & $8,10,11,14,18,20,212,22,24,26$ & \\
\hline $151,1,3,5,8,10,0,11,15,18,19,20,20,21,22,24,26$ & $13,15,22$ & 15,22 & \\
\hline $161,3,5,8,1,10,11,13,13,4,16,18,18,19,20,21,22,24,4,26$ & $8,11,12,13,16,17,17,18,20,22,24,26$ & $8,11,13,16,18,20,22,24,26$ & \\
\hline $17,1,3,5,8,10,10,11,13,1,14,16,17,1,18,19,20,21,22,2,24,26$ & $7,8,9,11,12,12,13,17,1,18,20,222,24,26,27$ & $8,11,13,17,1,18,20,22,24,26$ & \\
\hline $181,3,5,8,8,10,11,13,14,16,17,18,19,20,21,22,24,26$ & $8,10,11,12,13,14,14,15,16,17,18,18,20,21,222,26$ & $8,10,11,13,14,16,16,17,18,20,21,22,26$ & \\
\hline $195,10,13,19,20,21,22,22,24,26$ & $1,3,8,10,11,12,12,13,14,15,16,17,1,18,19,20,20,12,22,24,26$ & $10,13,19,20,21,22,2,24,26$ & \\
\hline $201,3,5,5,8,10,11,13,14,16,16,17,18,19,20,21,22,24,26$ & $1,3,5,5,10,10,11,12,13,14,15,16,17,17,19,19,20,21,22,24,26$ & $1,3,5,8,10,10,11,13,13,14,16,17,18,19,20,21,21,22,24,26$ & $\|$ \\
\hline $211,1,3,5,8,13,1,14,18,19,20,20,21,22,22,24,26$ & $1,3,5,8,10,10,11,12,13,13,14,15,16,16,17,18,19,20,20,21,22,24,26$ & $1,3,5,8,13,1,14,18,19,12,20,21,22,2,24,26$ & $\|$ \\
\hline $221,1,3,5,8,10,11,1,13,14,15,16,16,17,18,19,20,21,22,24,26$ & $1,3,5,8,10,11,11,12,13,14,15,16,16,17,18,19,20,21,21,22,24,26$ & $1,3,5,8,10,11,1,13,14,4,15,16,17,1,18,19,20,212,22,24,26$ & $\|$ \\
\hline $241,3,5,5,1,13,14,1,16,17,19,20,21,22,22,24,26$ & $1,3,5,8,10,0,11,12,13,13,14,15,16,16,17,18,19,20,2121,22,24,26$ & $1,3,5,5,13,13,14,16,17,19,29,20,21,22,24,2,26$ & $\|$ \\
\hline $261,3,5,5,1,13,14,16,17,18,19,20,21,22,24,26$ & $1,3,5,8,10,11,11,12,13,14,15,16,16,17,18,19,20,21,222,24,26$ & $1,3,5,5,13,13,14,16,17,1,18,19,20,20,21,22,24,26$ & $\|$ \\
\hline
\end{tabular}


Table VI. Iteration 3, Iteration 4, Iteration 5, Iteration 6,Iteration 7, Iteration 8

\begin{tabular}{|c|c|c|c|}
\hline REACHABILITY SET (Pi) & ANTECEDENT SET (Pi) & INTERSECTION & \\
\hline $11,3,8,10,13,19$ & $1,3,8,10,1,1,12,13,14,15,16,17,18$ & $1,3,8,10,13$ & \\
\hline $31,3,8,10,13,19$ & $1,3,8,10,11,1,1,13,14,15,16,17,18$ & $1,3,8,10,13$ & \\
\hline $81,3,8,13,14,16,17,18,19$ & $1,3,8,10,11,1,1,13,14,15,16,17,18$ & $1,3,8,13,14,16,17,18$ & \\
\hline $101,3,8,10,13,14,18,19$ & $1,3,10,11,12,13,14,15,16,17,18,19$ & $1,3,10,13,14,18,19,23$ & \\
\hline 11 1,3,8,10,11,13,14,16,17,18,19 & $11,12,13,14,15,16,17,18$ & $11,13,14,16,17,18$ & \\
\hline $121,3,8,10,11,12,13,14,16,17,18,19$ & 12 & 12 & \\
\hline $131,3,8,10,11,13,14,15,16,17,18,19$ & $1,3,8,10,11,12,13,16,17,18,19$ & $1,3,8,10,11,13,16,17,18,19$ & \\
\hline $141,3,8,10,11,14,18,19$ & $8,10,11,12,13,14,16,17,18$ & $8,10,11,14,18$ & \\
\hline $151,3,8,10,11,15,18,19$ & 13,15 & 15 & \\
\hline $161,3,8,10,11,13,14,16,18,19$ & $8,11,12,13,16,17,18$ & $8,11,13,16,18$ & \\
\hline $171,3,8,10,11,13,14,16,17,18,19$ & $7,8,9,11,12,13,17,18$ & $8,11,13,17,18$ & \\
\hline $181,3,8,10,11,13,14,16,17,18,19$ & $8,10,11,12,13,14,15,16,17,18$ & $8,10,11,13,14,16,17,18$ & \\
\hline $1910,13,19$ & $1,3,8,10,11,12,13,14,15,16,17,18,19$ & $10,13,19$ & III \\
\hline \multicolumn{4}{|c|}{ Table 6: teration 3} \\
\hline EMEN $\quad$ REACHABILITY SET (Pi) & ANTECEDENT SET (Pi) & INTERSECTION & \\
\hline $11,3,8,10,13$ & $1,3,8,10,11,12,13,14,15,16,17,18$ & $1,3,8,10,13$ & IV \\
\hline $31,3,8,10,13$ & $1,3,8,10,11,12,13,14,15,16,17,18$ & $1,3,8,10,13$ & IV \\
\hline $81,3,8,1,14,14,16,17,18$ & $1,3,8,10,11,12,13,14,15,16,17,18$ & $1,3,8,13,14,16,17,18$ & IV \\
\hline $101,3,8,10,13,14,18$ & $1,3,10,11,1,13,14,14,15,16,17,18$ & $1,3,10,13,14,18$ & \\
\hline 11 1,3,8,10,11,13,14,16,17,18 & $11,12,13,14,15,16,17,18$ & $11,13,14,16,17,18$ & \\
\hline $121,3,8,10,11,12,13,14,16,17,18$ & 12 & 12 & \\
\hline $131,3,3,10,11,13,14,15,16,17,18$ & $1,3,8,10,11,12,13,16,17,18$ & $1,3,8,10,11,1,13,16,17,18$ & \\
\hline $141,3,8,10,11,14,18$ & $8,10,11,12,13,14,16,17,18$ & $8,10,11,14,18$ & \\
\hline $151,3,8,10,11,15,18$ & 13,15 & 15 & \\
\hline $161,3,8,10,11,13,14,16,18$ & $8,11,12,13,16,17,18$ & $8,11,13,16,18$ & \\
\hline $171,3,8,10,11,13,14,16,17,18$ & $7,8,9,11,12,13,17,18$ & $8,11,13,17,18$ & \\
\hline $181,3,8,10,11,13,14,16,17,18$ & $8,10,11,12,13,14,15,16,17,18$ & $8,10,11,13,14,16,17,18$ & \\
\hline \multicolumn{4}{|c|}{ Table 7: Iteration 4} \\
\hline REACHABILITY SET (Pi) & ANTECEDENT SET (Pi) & INTERSECTION & \\
\hline $1010,13,14,18$ & $10,11,12,13,14,15,16,17,18$ & $10,13,14,18$ & $v$ \\
\hline 11 10,11,13,14,16,17,18 & $11,12,13,14,15,16,17,18$ & $11,13,14,16,17,18$ & \\
\hline $1210,11,12,13,14,16,17,18$ & 12 & 12 & \\
\hline $1310,11,13,14,15,16,17,18$ & $10,11,12,13,16,17,18$ & $10,11,13,16,17,18$ & \\
\hline $1410,11,14,18$ & $10,11,12,13,14,16,17,18$ & $10,11,14,18$ & $v$ \\
\hline $1510,11,15,18$ & 13,15 & 15 & \\
\hline $1610,11,1,1,14,16,18$ & $11,12,13,16,17,18$ & $11,13,16,18$ & \\
\hline $1710,11,1,1,14,16,17,18$ & $7,11,12,13,17,18$ & $11,13,17,18$ & \\
\hline $1810,11,13,14,16,17,18$ & $10,11,12,13,14,15,16,17,18$ & $10,11,13,14,16,17,18$ & $\boldsymbol{y}$ \\
\hline \multicolumn{4}{|c|}{ Table 8: iteration 5} \\
\hline REACHABILITY SET (Pi) & ANTECEDENT SET (Pi) & INTERSECTION & \\
\hline $1111,13,16,17$ & $11,12,13,15,16,17$ & $11,13,16,17$ & VI \\
\hline $1211,12,13,16,17$ & 12 & 12 & \\
\hline $1311,13,15,16,17$ & $11,12,13,16,17$ & $11,13,16,17$ & \\
\hline 1511,15 & 13,15 & 15 & \\
\hline $1611,13,16$ & $11,12,13,16,17$ & $11,3,1,16$ & VI \\
\hline $1711,13,16,17$ & $7,1,1,1,1,17$ & $11,3,17$ & \\
\hline \multicolumn{4}{|c|}{ Table 9: Leration 6} \\
\hline REACHABILITY SET (Pi) & ANTECEDENT SET (Pi) & INTERSECTION & \\
\hline $1212,13,17$ & 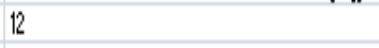 & 12 & \\
\hline $1313,15,17$ & $12,13,17$ & 13,17 & \\
\hline 1515 & 13,15 & 15 & VII \\
\hline 1713,17 & $12,13,17$ & 13,17 & YII \\
\hline \multicolumn{4}{|c|}{ Table 10: Iteration 7} \\
\hline REACHABILITY SET (Pi) & ANTECEDENT SET (Pi) & INTERSECTION & \\
\hline 1212,13 & 12 & 12 & \\
\hline 1313 & 12,13 & 13 & YIII \\
\hline \multicolumn{4}{|c|}{ Table 1t: iteration 8} \\
\hline REACHABILITY SET (Pi) & ANTECEDENT SET (Pi) & INTERSECTION & \\
\hline 1212 & 12 & 12 & IX \\
\hline
\end{tabular}

In the above process, the following are the levels found at various iterations:

- In the first iteration, elements 2, 4, 6, 7, 9, 23, 25 and 27 are found at level 1. 
- In the second iteration, 5, 20, 21, 22, 24 and 26 are found at level 2.

- In the third iteration, element 19 is found at level 3 .

Similarly, after eight iterations, all the levels are built for further construction of the ISM.

\section{Developing the Diagraph}

The final diagraph is developed that includes the transitive links. After the removal of indirect links in the obtained figure, the final diagraph is obtained that is shown in Fig 2.

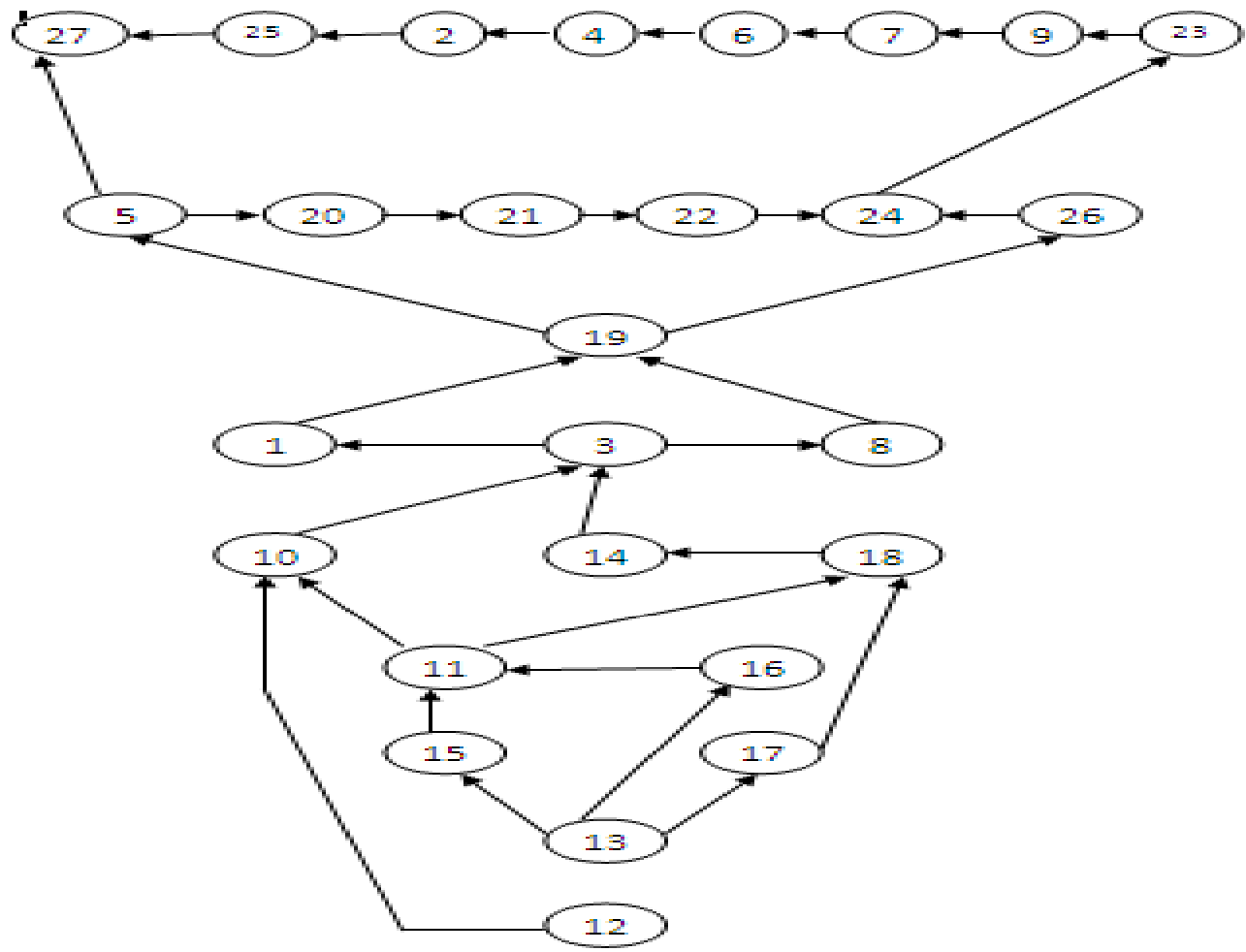

Fig 2: ISM-Based Model of the Variables That Affect the Acceptability of Neuro marketing in India Discussion

The results of the study indicate that acceptance of neuromarketing depends upon a lot of factors which can be controlled. The top-level variables have weak driving power and strong dependence on other variables. With the help of the obtained diagraph, it can be clearly seen that the bottom variables like strong literature and academic evidences are the base for getting effective results out of this market research technique. As building up gradually in the model, the variables contribute more towards achieving trust in research, new technology adoption, accuracy in research, high impact ad-campaigns, new product development opportunities etc. These variables have the capability to condition the overall market research process and can be called independent elements or drivers of acceptability of a technique like neuromarketing in India. The companies should focus upon adopting strategies for focusing more on the driving variables in order to achieve the dependence variables obtained in the diagraph.

\section{FUTURE SCOPE AND LIMITATIONS}

In the present work only twenty seven variables are identified for modeling acceptance of neuromarketing. More number of variables can be identified to develop ISM. The experts' help have been sought to analyze driving and dependence power of the variables. Here the framework developed depends upon the opinion of few experts and may have some element of bias. Through ISM, a relationship model among the variables has been developed. This model has not been statistically validated. Structural equation modeling (SEM) has the capability of testing the validity of the model. Therefore, it may be applied in the future research to test the validity of this model. 


\section{REFERENCES}

[1] True Impact Marketing Inc. (2013, November 3). Neuromarketing Theory and Practice Magazine. Retrieved from http://www.trueimpact.ca/: http://www.trueimpact.ca/neuromarketing-theory-and-practice-magazine/

[2] Agarwal, A., Shankar, R., \& Tiwari, M. (2007). Modeling agility of supply chain. Industrial Marketing Management, $443-457$.

[3] Ambler, T., Ionnaides, A., \& Rose, S. (2000). Brand on the brain-Neuroimages of advertising. Business strategy review, 11(3), pp. 1730 .

[4] Barkin, E. (2013). The Prospects and Limitations of Neuromarketing. Retrieved from http://www.destinationcrm.com/: http://www.destinationcrm.com/Articles/Editorial/Magazine-Features/The-Prospects-and-Limitations-of-Neuromarketing-90150.aspx

[5] Bayers, C. (2011, october 03). This Is Your Brain on Marketing Up close and personal with fMRI. Retrieved october 25, 2012, from www.adweek.com: http://www.adweek.com/news/advertising-branding/your-brain-marketing-135355

[6] Bercea, M. D. (2011). Anatomy of methodologies for measuring consumer behavior in neuromarketing research. Romanian National Authority. Retrieved from http://www.lcbr-online.com/index_files/proceedingsemc12/12emc023.pdf

[7] Bercea, M. D. (2012, November 09). NMSBA ANNOUNCES THE NEUROMARKETING CODE OF ETHICS. Retrieved November 11, 2012, from http://neurorelays.wordpress.com: http://neurorelays.wordpress.com/2012/11/09/nmsba-announces-theneuromarketing-code-of-ethics/

[8] BORICEAN, V. (2009). BRIEF HISTORY OF NEUROMARKETING. The International Conference on Administration and Business (pp. 119-121). University of Bucharest, Romania: Doctoral School of Economics, "Al. I. Cuza” University - Iaşi.

[9] Burney, M. (2012, October 06). "Brandwashed” by Neuromarketing? Retrieved November 05, 2012, from http://blogs.ubc.ca: http://blogs.ubc.ca/mayaburney/2012/10/06/brandwashed-by-neuromarketing/

[10] Burney, M. (2012, October 6). "Brandwashed" by Neuromarketing?

[11] carte blanche. (2013). Neuromarketing: Ethical shopping Behaviour. Retrieved from http://mtl-carteblanche.com/: http://mtlcarteblanche.com/neuromarketing-ethical-shopping.html

[12] Ciprian-Marcel, P., Lăcrămioara, R., Ioana, M. A., \& Maria, Z. M. (2009). NEUROMARKETING - GETTING INSIDE THE CUSTOMER'S MIND. Annals of Faculty of Economics, 804-807.

[13] Corcoran, D. (1999). NeuroMarketing - Top 7 Insights To Unlocking Your Customer's Brain For Instant Sales. Retrieved November 13, 2012, from http://www.businessknowhow.com: http://www.businessknowhow.com/marketing/neuromarketing.htm

[14] Demirbilek, O. (2013, November 3). subconscious emotional appeal of products. Retrieved from unsworks.unsw.edu.au/: unsworks.unsw.edu.au/fapi/datastream/unsworks:3109/SOURCE1

[15] Dooley, R. (2007, April 24). Simple Marketing for Complex Products. Retrieved from Neuromarketing-Where Brain and Science Meets: http://www.neurosciencemarketing.com/blog/articles/simple-marketing-for-complex-products.htm

[16] Dooley, R. (2012, June 06). Democrats \& Republicans Disagree on Brands, Too. Retrieved November 20, 2012, from http://www.forbes.com: http://www.forbes.com/sites/rogerdooley/2012/06/14/blue-red-brand/

[17] Dooley, R. (2013, November 4). Neuromarketing: For Coke its a Real Thing. Retrieved from http://www.forbes.com/: http://www.forbes.com/sites/rogerdooley/2013/03/07/coke-neuromarketing/

[18] Eser, Z., Isin, F. B., \& Tolon, M. (2011). Perceptions of marketing academics, neurologists, and marketing professionals about neuromarketing. Journal of Marketing Management, 27(7-8), 854-868.

[19] Eser, Z., Isin, F. B., \& Tolon, M. (2011). Perceptions of marketing academics, neurologists, and marketing professionals about neuromarketing. Journal of Marketing Management, 854-868.

[20] Fabiano Communications. (2013, November). Harness Converging Technologies and Diverging Audiences to Create Dynamic One to One Marketing and Astonishing ROI. Retrieved from http://www.neuromarketology.com/.

[21] Fisher, C. E., Chin, L., \& Klitzman, R. (2010). Defining Neuromarketing: Practices and Professional Challenges. Harv Rev Psychiatry, 230-237.

[22] Genco, S. (2013, June 2). Neuroethics: Some principles. Retrieved from http://www.intuitiveconsumer.com/: http://www.intuitiveconsumer.com/blog/item/17

[23] Gert, B. (2002, April 17). The Definition of Morality. Retrieved November 03, 2012, from The Stanford Encyclopedia of Philosophy (Fall 2012 Edition): http://plato.stanford.edu/entries/morality-definition/

[24] Green, S., \& Holbert, N. (2012, May 04). GIFTS OF THE NEURO-MAGI:Science and speculation in the age of neuromarketing. $\begin{array}{llll}\text { Retrieved } \quad \text { November } & \text { 2012, from }\end{array}$ http://www.marketingpower.com/ResourceLibrary/MarketingResearch/Pages/2012/Spring\%202012/Gifts-of-the-Neuro-Magi.aspx

[25] J. S. Rakshi1, T. U. (1999). Frontal, midbrain and striatal dopaminergic function in early and advanced Parkinson's disease A 3D [18F]dopa-PET study. Brain-Ajournal of Neurology, Pp. 1637-1650. Retrieved from http://brain.oxfordjournals.org: http://brain.oxfordjournals.org/content/122/9/1637.long

[26] Javor, A., Koller, M., Lee, N., Chamberlain, L., \& Ransmay, G. (2013, November 2). Neuromarketing and consumer neuroscience: contributions to neurology. Retrieved from http://www.biomedcentral.com/: http://www.biomedcentral.com/1471-2377/13/13\#B20

[27] Johnson, A. (2011, February 6). Nielsen IPO Raises Awareness for Neuromarketing. Retrieved November 25, 2012, from http://videos.webpronews.com: http://videos.webpronews.com/2011/02/nielsen-ipo-raises-awareness-for-neuromarketing/

[28] Joseph, R. (2000). Striatum, Basal Ganglia, Thalamus Striatum, Basal Ganglia, Thalamus Parkinson's Disease, Alzheimer's Psychosis, Catatonia, Obsessive-Compulsions \& Disorders of Movement. Retrieved october 26, 2012, from www.brainmind.com: http://brainmind.com/BasalGanglia.html

[29] Khot, G., Parekh, A., \& Talokar, A. (2011, August). NeuroMarketing: Inside the Black Box. Markathon: Marketing Magazine of IIM Shillong, III(2), 4-7.

[30] Kyriaki, K. (2012). Neuromarketing: Validity and Morality. The Swedish School of Textiles, Borås .

[31] Levy, N. (2009). Neuromarketing: Ethical and Political Challenges. Etica \& Politica / Ethics \& Politics, 10-17.

[32] Mizushima, N., \& Osamu, S. (2012). A Practical Approach to Identifying Ethical and Social Problems during Research and Development: A Model for a National Research Project of Brain-Machine Interface. East Asian Science, Technology and Society: An International Journal, 335-345.

[33] Morin, C. (2011, January 14). Neuromarketing: The New Science of Consumer Behavior.

[34] NeuroFocus, Inc. (2012). What is neuromarketing. Retrieved november 11, 2012, from www.neurofocus.com: http://www.neurofocus.com/in/neuromarketing.htm

[35] Neuromarketing Science \& Business Association. (2013, November 2). NMSBA Code of Ethics. Retrieved from http://www.nmsba.com/: http://www.nmsba.com/ethics 
[36] Neurosense. (2013, October). New Product Development. Retrieved from Neurosense Web Site: http://www.neurosense.com/

[37] Ozdemir, M., \& Koc, M. (2012). Two Methods of Creative Marketing Research: Neuromarketing and In-depth Interview. International Scientific journal, 113-117.

[38] Reason, G. (2013, November 2). Neuromarketing is dead. Long live neuromarketing. Retrieved from http://www.essencedigital.com/: http://www.essencedigital.com/blog/2012/11/neuromarketing-is-dead-long-live-neuromarketing/

[39] Roberson, M.-R. (2012). Duke Student Finds New Markets for Neuromarketing. Retrieved from http://entrepreneurship.duke.edu/: http://entrepreneurship.duke.edu/news/\%5Btitle\%5D-1

[40] Sakura, O., \& Mizushima, N. (2009). Towards the Governance of Neuroscience: Neuroethics in Japan with Special Reference to Brain-Machine Interface (BMI). East Asian Science, Technology and Society: An International Journal, 137-144.

[41] Somani, P. (n.d.). NeuroMarketing: Where Brain, Science and Market meet. Retrieved November 28, 2012, from www.pearlsomani.com: www.pearlsomani.com/downloads/NeuroMarketing_Pearl.pdf

[42] Wald, P. (2011, june 10). www.pedrowald.com. Retrieved november 4, 2012, from http://www.pedrowald.com/: http://www.pedrowald.com/?p=312

[43] Walvis, T. H. (2007). Three laws of branding: Neuroscientific foundations of effective brand building. Brand Management, 176-194.

[44] Wikipedia. (2008, May 21). Paul MacLean's Brain Model. Retrieved October 25, 2012, from www.wordpress.com: http://gamesbaseball.wordpress.com/2008/05/21/paul-macleans-brain-model/

[45] Wikipedia ${ }^{\circledR}$. (2011, July 2011). Steady State Topography. Retrieved october 25, 2012, from www.en.wikipedia.org: http://en.wikipedia.org/wiki/Steady_state_topography

[46] Wikipediaß. (2012, november 22). www.en.wikipedia.org. Retrieved november 30, 2012, from www.wikipedia.org: http://en.wikipedia.org/wiki/Neuromarketing

[47] WILSON, R. M., GAINES, J., \& HILL, R. P. (2008). Neuromarketing and Consumer Free Wil. The Journal of Consumer Affairs, 389410.

[48] Zurawicki, L. (2010). Neuromarketing: Exploring the Brain of the Consumer. New York: Springer Heidelberg Dordrecht. 